\title{
Musculoskeletal symptoms and work ability among agricultural machinery operators
}

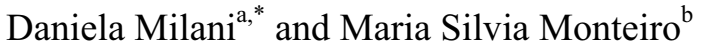 \\ ${ }^{a}$ Nursing Post-Graduate Program, Federal University of São Carlos, PO box 676, São Carlos, SP, Brazi1, 13565-905 \\ ${ }^{\mathrm{b}}$ Nursing Department, Federal University of São Carlos, PO box 676, SãoCarlos, SP, Brazil, ZIP Code 13565-905
}

\begin{abstract}
Those subjects whose employment has physical demands present more frequently musculoskeletal symptoms than others. The agricultural sector activities include tasks with important physical demands that may have a negative impact in the workers health. The aim of this study was to evaluate the presence of musculoskeletal symptoms and its association with work ability in agricultural machinery operators. It is a cross-sectional study. The participants $(n=204)$ answered a self-administered questionnaire on demographics, work and lifestyle characteristics, Work Ability Index and the Nordic Musculoskeletal Symptoms Questionnaire. The response rate was $89.78 \%$. The mean age of the workers was 32.3 years, and $47.1 \%$ of them reported musculoskeletal symptoms at least one body part over the past 12 months. Those subjects who presented work ability index $<37$ points, $87.5 \%$ reported some kind of musculoskeletal symptom. This study showed that the work ability was significantly $(\mathrm{p} \leq 0.05)$ correlated to musculoskeletal symptoms presence. It is recommended that measures to promote and improve the work ability are designed and deployed based on musculoskeletal disorders prevention.
\end{abstract}

Keywords: Occupational Health, Cross-sectional studies, Sugar-cane workers;

\section{Introduction}

Those subjects whose employment has physical demands present more frequently injuries than others. The musculoskeletal disorders are the most common among these injuries [3]. These disorders have been an important cause for work ability decrease among workers [8]. The agricultural sector activities include tasks with important physical demands that may have a negative impact in the workers health [7].

The aim of this study was to evaluate the presence of musculoskeletal symptoms and its association with the work ability in agricultural machinery operators.

\section{Materials and Methods}

\subsection{Study description}

This is a cross-sectional population-based study about the musculoskeletal symptoms and work abil- ity among agricultural machinery operators in a Brazilian sugar and ethanol industry.

\subsection{Subjects and Ethical Aspects}

The study included 204 machinery operators and the response rate was $89.87 \%$. All the selected operators satisfied the following criteria: (i) Be working in data collection period; (ii) minimum agricultural machinery operating experience of 1 year; (iii) minimum education of 8 years; (iv) to accept participate of the study. The research project of this study was approved by the ethics committee from the Federal University of Sao Carlos, protocol number 400/2009 and written informed consent was obtained from each subject.

\subsection{Data Collection}

Data were collected by self-administered questionnaire, on demographics, work and lifestyle char-

\footnotetext{
*Corresponding author. Tel.: +551496178606. E-mail adress: danmilani@bol.com.br.
} 
acteristics. In addition, were included the Work Ability Index and the Nordic Musculoskeletal Symptoms questionnaires.

\subsubsection{The Work Ability Index (WAI)}

The WAI is a self-administered questionnaire used in clinical occupational health and research to asses work ability during health examinations and workplace surveys [4]. This instrument was developed by the Finnish Institute of Occupational Health and aims to: identify early work ability decline, carry on the preventive measures and rehabilitation effects, and to assess the work disability. It has been used in studies of various countries than Finland [4]. The Brazilian version was translated in 2005 [12] and was based on English version of 1998 [11].

\subsubsection{The Nordic Musculoskeletal Questionnaire}

This questionnaire evaluates presence of musculoskeletal disorders in the population studied and the part of human body affected [1,5]. This is an internationally respected instrument with an ergonomic approach. It is considered for simple application, and understanding $[1,5]$. It consists of questions regarding parts of the human body that correspond to nine anatomical areas, marked on illustration of the human body seen from behind [5]. The interviewee answer yes or no for questions about: annual and weekly prevalence; functional incapacity; and search for medical assistance in the last 12 months [1].

\subsection{Data Analysis}

Data were analyzed using R: A language and environment for statistical computing (version.2.5.1). For the analysis of association about categorical variables used the chi-square or Fisher test. An univariate logistic regression analysis was performed to identify factors associated with the presence of musculoskeletal symptoms in the last 12 months.

In this analysis, the presence of musculoskeletal symptoms was the dependent variable. The independent variables were: WAI score ( $<37 x \geq 37$ points), age $(<35 \mathrm{X} \geq 35$ years) and $(<45 \mathrm{X} \geq 45$ years), education $(<8$ $\mathrm{X} \geq 8$ years) and physical activities (yes/no). The results were considered significant when $p$-values $\leq 0.05$.

\section{Results}

The mean age of the machinery operators was 32.3 years. The average duration of work at the institution was 5.4 years. Considering at least one body part, the musculoskeletal symptoms presence over the past 12 months was reported by $47.1 \%$ of the workers. Those body parts affected are represented in the Figure 1.

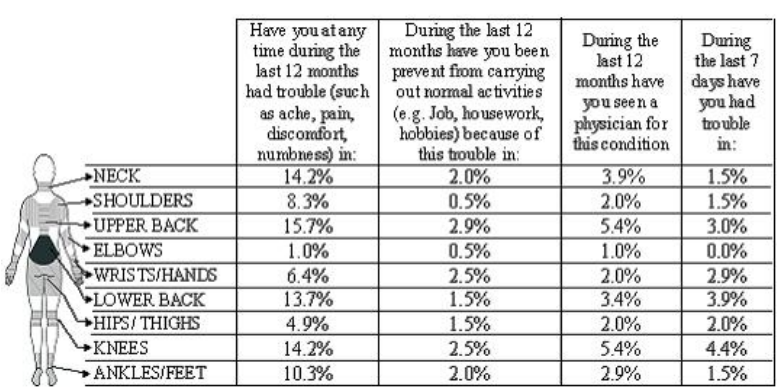

Fig.1. Musculoskeletal symptoms of the machinery operators regarding body parts $(n=204)$

The work ability was significantly correlated to the presence of musculoskeletal symptoms. Those subjects who presented work ability index $<37$ points, $87.5 \%$ reported some kind of musculoskeletal symptom. These data are presented in Table 1

The univariate logistic regression analysis showed that the WAI was related to musculoskeletal symptoms (Table 2).

\section{Discussion}

The frequency of musculoskeletal symptoms in the last 12 months was not as high as pointed out by other studies [6] but the fact that $47.1 \%$ of the operators has reported these symptoms may be significant, as they working time in the institution and age of them are relatively low compared with the working time and age of the others studies observed. The healthy worker effect [10] also should be a factor to be taken into account.

Regarding work ability and musculoskeletal symptoms, the shoulders, wrists and hands body parts symptoms were associated with work ability, however them had not been the most frequently body parts reported by the machinery operators. This may mean that these body parts when affected; they are those most disabling for the performance of tasks related to agricultural machinery occupation. This corroborates what was reported by researchers [2] that argue those musculoskeletal symptoms in other body parts beyond lower back has not been enough attention.

The univariate logistic regression analysis about the presence of musculoskeletal symptoms and work ability confirm what was found in other study [9] in which WAI is strongly associated with issues of health status. 
Table 1

Work ability of machinery operators according musculoskeletal symptoms in general and in specific body parts at the last 12 months

\begin{tabular}{|c|c|c|c|c|c|c|c|}
\hline \multirow[t]{3}{*}{ Variable } & \multirow[t]{3}{*}{ Category } & \multicolumn{4}{|c|}{ Work Ability } & \multirow{3}{*}{$\begin{array}{l}\text { Total } \\
\mathrm{n}\end{array}$} & \multirow[t]{3}{*}{ P Value $^{a}$} \\
\hline & & \multicolumn{2}{|c|}{$<37$} & \multicolumn{2}{|c|}{$\geq 37$} & & \\
\hline & & $\mathrm{n}$ & $\%$ & $\mathrm{~N}$ & $\%$ & & \\
\hline \multirow{2}{*}{$\begin{array}{l}\text { Musculoskeletal Symptoms } \\
\text { in general }\end{array}$} & Yes & 7 & 7.3 & 89 & 92.7 & 96 & \multirow[t]{2}{*}{0.0200} \\
\hline & No & 1 & 1.0 & 107 & 99.0 & 108 & \\
\hline \multirow[t]{2}{*}{ Neck } & Yes & 3 & 10.3 & 26 & 89.7 & 29 & \multirow[t]{2}{*}{0.0884} \\
\hline & No & 5 & 2.9 & 170 & 97.1 & 175 & \\
\hline \multirow[t]{2}{*}{ Shoulders } & Yes & 3 & 17.6 & 14 & 82.4 & 17 & \multirow[t]{2}{*}{0.0209} \\
\hline & No & 5 & 2.7 & 182 & 97.3 & 187 & \\
\hline \multirow[t]{2}{*}{ Upper back } & Yes & 2 & 6.3 & 30 & 93.8 & 32 & \multirow[t]{2}{*}{0.6140} \\
\hline & No & 6 & 3.5 & 166 & 96.5 & 172 & \\
\hline \multirow[t]{2}{*}{ Elbows } & Yes & 0 & - & 2 & 100.0 & 2 & \multirow[t]{2}{*}{$n s$} \\
\hline & No & 8 & 4.0 & 194 & 96.0 & 202 & \\
\hline \multirow[t]{2}{*}{ Wrists/ Hands } & Yes & 3 & 23.1 & 10 & 76.9 & 13 & \multirow[t]{2}{*}{0.0095} \\
\hline & No & 5 & 2.6 & 186 & 97.4 & 191 & \\
\hline \multirow[t]{2}{*}{ Lower back } & Yes & 1 & 3.6 & 27 & 96.4 & 28 & \multirow[t]{2}{*}{$n s$} \\
\hline & No & 7 & 4.0 & 169 & 96.0 & 176 & \\
\hline \multirow[t]{2}{*}{ Hips/Thighs } & Yes & 1 & 10.0 & 9 & 90.0 & 10 & \multirow[t]{2}{*}{0.3359} \\
\hline & No & 7 & 3.6 & 187 & 96.4 & 194 & \\
\hline \multirow[t]{2}{*}{ Knees } & Yes & 1 & 3.4 & 28 & 96.6 & 29 & \multirow[t]{2}{*}{$n s$} \\
\hline & No & 7 & 4.0 & 168 & 96.0 & 175 & \\
\hline \multirow[t]{2}{*}{ Ankles/feet } & Yes & 2 & 9.5 & 19 & 90.5 & 21 & \multirow[t]{2}{*}{0.1935} \\
\hline & No & 6 & 3.3 & 177 & 96.7 & 183 & \\
\hline
\end{tabular}

Table 2

Univariate Logistic Regression analysis of the age, physical activities, education and work ability index in relation to presence of musculoskeletal symptoms in the last 12 months

\begin{tabular}{llll}
\hline Variable & P-valor & $\mathrm{OR}^{\mathrm{a}}$ & $95 \% \mathrm{CI}^{\mathrm{b}}$ \\
\hline Age $(<45 \mathrm{x} \geq 45$ years $)$ & 0.1095 & 2.6896 & $0.8006 ; 9.0355$ \\
Age $(<35 \mathrm{x} \geq 35$ years $)$ & 0.398 & 0.7793 & $0.4372 ; 1.3891$ \\
Physical activity (yes $\mathrm{x}$ no) & 0.1085 & 1.5759 & $0.9042 ; 2.7465$ \\
Education $(<8 \mathrm{x} \geq 8$ years $)$ & 0.431 & 0.7954 & $0.4496 ; 1.4069$ \\
WAI $(<37 \mathrm{x} \geq 37$ points $)$ & 0.0483 & 0.1188 & $0.0143 ; 0.9841$ \\
\hline${ }^{\mathrm{a}} \mathrm{OR}=$ Odds Ration & \multicolumn{3}{c}{$\mathrm{b} 95 \% \mathrm{CI}=95 \%$ Confidence Interval }
\end{tabular}

\section{Conclusion}

Considering the relationship between work ability and musculoskeletal symptoms it is recommended that measures to promote and improve the work ability are designed and deployed based on musculoskeletal disorders prevention.

\section{References}

[1] Barros, E.N.C, Alexandre, N.M.C, 2003. Cross-cultural adaptation of the Nordic musculoskeletal questionnaire. Int. Nurs. Rev. 50, n.2. 101-108.

[2] Hagberg, M., Burström, L., Ekman, A., Vilhelmsson, R., 2006. The association between whole body vibration exposure and musculoskeletal disorders in the Swedish work force is confounded by lifting and posture. J. Sound Vib. 298, 492-498.

[3] Ilmarinen, J., 2001. Aging workers. Occup. Environ. Med. 58, 546-552.
[4] Ilmarinen, J., 2007. The Work Ability Index (WAI). Occup. Med. 58, 160 .

[5] Kuorinka, I., Jonsson, B., Kilbom, A., Vinterberg, H. BieringSørensen, F., Andersson, G., Jørgensen, K., 1987. Standardized Nordic Questionnaires for the Analyses of Musculoskeletal Symptoms. Appl. Ergon. 18, 233-237.

[6] Mayton, A.G, Kittusamy, N.K, Ambrose, D.H, Jobes, C.C, Legault, M.L, 2008. Jarring/jolting exposure and musculoskeletal symptoms among farm equipment operators. Int. J. Ind. Ergon. 38, 758-66.

[7] Mehta, C.R., Tewari, V.K., 2000. Seating discomfort for tractor operators- a critical review. Int. J. Ind. Ergon. 25, 661-674.

[8] Monteiro, M.S, Alexandre, N.M.C, Rodrigues, C.M, 2006. Musculoskeletal diseases, work and lifestyle among public workers at a health institution. Rev. Esc. Enferm. USP. 40, 20-25.

[9] Savinainen, M., Nygård, C.H., Ilmarinen, J., 2004. Workload and physical capacity among ageing municipal employees-a 16 year follow-up study. Int. J. Ind. Ergon. 34, 519-533.

[10] Shah, D., 2009. Health work effect phenomenon. Indian J. Occup. Environ. Med. 13, 77-79.

[11] Tuomi, K, Ilmarinen, J, Jahkola, A., Katajarinne, L., Tulkki, A., 1998. Work ability index. 2nd edition. Translated by Georgianna Oja. Helsinki, Finnish Institute of Occupational Health.

[12] Tuomi, K., Ilmarinen, J., Jahkola, A., Katajarinne, L., Tulkki, A., 2005. Índice de capacidade para o trabalho. 2a ed. Trad de Fisher FM. Org. Sao Carlos: EdUFSCar. 60p.

[13] Tuomi, K., Ilmarinen, J., Klockars, M., Nygard, C.H., Seitsamo, J., Huuhtanen, P., Martikainen, R., Aalto, L., 1997. Finish research project on aging workers in 1981-1992. Scand. J. Environ. Health 23 (Suppl. 1) 7-11.

[14] Tuomi, K., Ilmarinen, J., Seitsamo, J., Huuhtanen, P., Martikainen, R., Nygard, C.H., Klockars, M., 1997. Summary of Finish research project (1981-1992) to promote the health and 
work ability of aging workers. Scand. J. Environ. Health, 23

(Suppl. 1), 66-71. 